\title{
Erectile dysfunction and its management in patients with diabetes mellitus
}

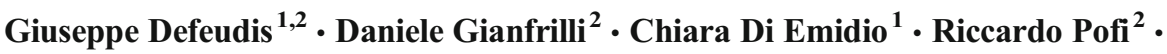 \\ Dario Tuccinardi ${ }^{1} \cdot$ Andrea Palermo $^{1} \cdot$ Andrea Lenzi $^{2} \cdot$ Paolo Pozzilli $^{1}$
}

(C) Springer Science+Business Media New York 2015

\begin{abstract}
Diabetes can be described as a syndrome of multiple closely related conditions induced by a chronic state of hyperglycaemia resulting from defective insulin secretion, insulin action or both. Chronic complications associated with diabetes (including neuropathy, vascular disease, nephropathy and retinopathy) are common, and of these, erectile dysfunction (ED) deserves special attention. ED and its correlation with cardiovascular disease require careful evaluation and appropriate treatment. PDE5 inhibitors (PDE5is) are an important tool for the treatment of ED, with new drugs coming onto the market since the late 90s. This review offers an overview of PDE5is and their use in treating ED in diabetes. We underline the differences between different types of PDE5i, focusing on available doses, duration of action, $\mathrm{T} 1 / 2$, side effects and selectivity profiles in relation to patients with diabetes. We also discuss the link between diabetes and ED in presence of various associated cofactors (obesity, hypertension and its pharmacological treatments, atherosclerosis, hyperhomocysteinaemia, neuropathy, nephropathy, hypogonadism and depression). Finally a number of past and ongoing clinical trials on the use of PDE5is in patients with diabetes are presented to offer an overview of the appropriate treatment of ED in this condition.
\end{abstract}

Giuseppe Defeudis and Daniele Gianfrilli have an equal contribution.

Paolo Pozzilli

p.pozzilli@unicampus.it

1 Department of Endocrinology and Diabetes, University Campus Bio-Medico of Rome, Via Alvaro del Portillo 21, Rome, Italy

2 Department of Experimental Medicine, Sapienza University of Rome, Viale del Policlinico 155, Rome, Italy
Keywords Diabetes mellitus · Erectile dysfunction · PDE-5 inhibitors $\cdot$ Diabetes complications

The incidence of diabetes has risen rapidly in recent years and its global prevalence is predicted to increase. Its complications including erectile dysfunction (ED) represent a serious health, economic and social problem. The purpose of this review is to evaluate the link between diabetes and ED and to analyse current treatments and novel approaches to this complication.

\section{Erectile dysfunction in patients with diabetes}

\subsection{Physiology of penile erection}

Penile erection (PE) is a complex mechanism resulting in penis tumescence, which begins after central processing and integration of visual, tactile, imaginative and olfactory stimuli. An information network of primary afferents from the genitals, spinal interneurons and sympathetic, parasympathetic and somatic nuclei starts from the spinal cord. Peripherally, contraction (or relaxation) of the cavernosal smooth muscle controls the function of the penis [1], determining whether it is erect or flaccid. When flaccid, the cavernosal smooth muscle is contracted leading to a partial oxygen pressure (PO2) in the blood of around $35 \mathrm{mmHg}$ [2]. In contrast, penile erection is characterised by increased blood flow and pressure into the lacunar space, so that the venous outflow is reduced by compression of venular spaces between the tunica albuginea and peripheral sinusoids, with an increase in intracavernosal pressure to approximately $100 \mathrm{mmHg}$ [3]. 


\subsection{Mechanisms mediating erection and penile relaxation}

PE requires the relaxation of the cavernosal smooth muscle. The diffusion of substances deriving from the parasympathetic and non-adrenergic non-cholinergic nerves promotes vascular and cavernosal relaxation and an increase in blood flow and intracavernosal pressure, resulting in erection [4].

Nitric oxide (NO) is the most important and effective of the vasodilators included in this process [5]. In the penis, NO is produced by eNOS activation, mediated by noradrenalin and calcium entry into the cell [6]. Two intracellular mechanisms for relaxing the cavernosal smooth muscle can be identified: the guanylate cyclase (GS)/cGMP and adenylate cyclase/ cAMP pathways. The first, called the NO/cGMP pathway, leads to the diffusion of NO into adjacent smooth muscle cells of the corpora cavernosa, where it binds to soluble guanylyl cyclase (GC), catalysing the passage from guanosine trisphosphate (GTP) to cGMP; this induces PE through decreasing cytosolic $\mathrm{Ca}^{2+}$ and increasing blood flow into the corpora cavernosa. The second involves prostaglandin E1 (PGE1). This activates the enzyme adenylate cyclase, catalysing the conversion of adenosine monophosphate (AMP) to cyclic AMP (cAMP), which also decreases the intracellular $\mathrm{Ca} 2+$ [7]. Both cGMP and cAMP levels are modulated by phosphodiesterase (PDE) enzymes, which enable their respective transition to 5' GMP and 5'AMP.

Phosphodiesterase-5 (PDE5) is an enzyme present in the NO/cGMP pathway which helps modulate smooth muscle cell relaxation and the erectile process [5]. It is strongly expressed in the corpora cavernosa, in which the hydrolysis of cGMP to the inactive metabolite 5' GMP is catalysed.

A third mechanism involved in PE is the phosphatidylinositol 3-kinase (PI3-kinase) pathway, which also reduces the enzyme's calcium requirement and increases $\mathrm{NO}$ production.

\subsection{Flaccidity and detumescence}

Flaccidity and detumescence are linked to the sympathetic nervous system, which acts on the cavernosal arteries through adrenergic enervation and norepinephrine $[8,9]$. Endothelins (endothelin-1 (ET-1)) [10], synthesised by penile smooth muscle cells, take part in the transition to the flaccid state through Endothelin receptor Type A (ETA), involving activation of the inositol trisphosphate (IP3)/calcium $\left(\mathrm{Ca}^{2+}\right)$ and RhoA/Rhokinase signalling pathways [11].

$\mathrm{G}$ protein activation keeps the cavernosal arterioles and sinuses closed, enabling a non-erect state. RhoA/Rho-kinase activity is an important component in keeping the penis flaccid. This pathway is upregulated in $\mathrm{ED}$, in which the equilibrium between penile contraction and relaxation by the RhoA/Rho-kinase and NO/cyclic-GMP pathways is almost unbalanced [12].
The phospholipase C (PLC) pathway is another mechanism involved in penile vasoconstriction in the absence of arousal stimuli. The vasoconstrictor agonists include norepinephrine (NE), angiotensin II (Ang II), ET-1 and others that stimulate PLC. This stimulation causes the final release of $\mathrm{Ca}^{+}$ ${ }^{2}$ from the intracellular stores.

\subsection{Mechanisms mediating erectile dysfunction in diabetes}

ED is induced by a combination of neurogenic [13], vasculogenic [14], endocrinological and metabolic [15, 16], drug-induced [17] and psychological [18] causes. It can be classified as psychogenic, organic or mixed psychogenic and organic [14].

In patients with diabetes, some of these physiological mechanisms are the result of compromises which induce ED as a "side effect". In diabetes, hyperglycaemia is associated with increased oxidative stress $[19,20]$, due to an overproduction of advanced glycation end products (AGEs), hexosamine and protein kinase $\mathrm{C}(\mathrm{PKC})$ and increased stimulation of the polyol pathway [20] (Fig. 1). Hyper-production of reactive oxygen species (ROS) is behind the evolution of macrovascular and microvascular complications, including neuropathy. Endothelial dysfunction is due to a complex set of events. Reduced NO and increased production of prothrombotic factors such as tissue factor and plasminogen activator inhibitor-1, or an increase in ET-1 [21] induce, thrombosis and vasoconstriction, respectively, while an increase in nuclear factor kappaB (NF- $\mathrm{kB})$ and activator protein 1 (AP-1) leads to tissue inflammation [22].

Neuropathy is a relevant pathogenic factor in inducing ED affecting all levels of the neural system and the erection process [21]. Kamenov et al. in 2007 demonstrated that microangiopathy, and in particular diabetic nephropathy, is a more important predisposing factor for ED in patients with diabetes than macroangiopathy [23].

Hyperglycaemia has an important role in the pathophysiology of ED and promotes a cascade of events culminating in ED, producing a sort of "diabetic erectile dysfunction wall" (Fig. 1).

\subsection{Epidemiology of ED in patients with and without diabetes}

ED is a clinical disorder mainly affecting men above the age of 40 . Recent studies show that its prevalence in men under 40 is $1-10 \%$ [24]. This increases to $20-40 \%$ in men of 60 69 years of age and to $50-100 \%$ in men above 70 [25]. The Massachusetts Male Aging Study, a long term follow-up analysis, showed that the incidence of ED ranges from 26 per 1000 man-years (crude incidence) to 46 per 1000 man-years for men of 60-69 years of age. The same study predicted that 
Fig. 1 The "diabetic erectile dysfunction wall". This is a representation of the intercurrent pathophysiology between diabetes and one of its complications. AGEs advanced glycation end-products, $P O L Y O L$ $P A T H$. polyol pathway, $P K C$ protein kinase $\mathrm{C}, R O S$ reactive oxygen species, $N O$ nitric oxide, ET-1 endothelin-1, PAI-1 Plasminogen activator inhibitor$1, A P-1$ activator protein 1

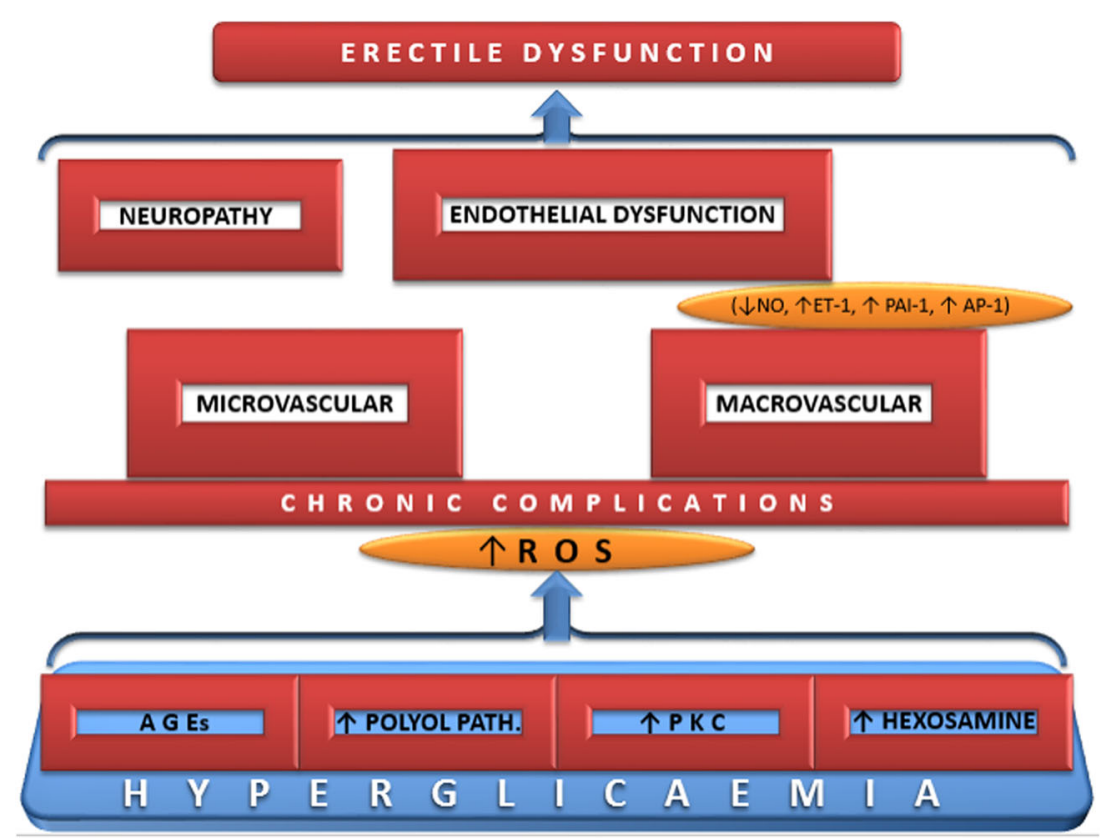

erectile dysfunction will affect 322 million men worldwide by $2025[3,26,27]$.

Several studies have demonstrated an increased incidence of ED in patients with diabetes. Epidemiological data are strongly dependent on age, duration, type of DM and the diagnostic criteria used [21]. ED develops about 10 years earlier in diabetic men than in the general population [26] and is more serious, diminishing health-related quality of life [28]. More than $50 \%$ of diabetic men have sexual dysfunction and this incidence is greater in patients under pharmacological treatment for diabetes due to a linear ratio between the disease's duration, beta cell damage and the need for new medications [29-32]. Almost none of the studies differentiated between T1D and T2D, so it is not simple to determine any significant differences in the incidence and prevalence of ED between these two categories of patients. However, studies that did differentiate between T1D and T2D found a similar prevalence of ED in both groups after adjusting for age [29, 31]. In men with diabetes, the severity of ED increases with age, duration of diabetes, poor glycaemic control and presence of microvascular complications [29].

Men with T1D and T2D are at a significantly higher risk of ED than nondiabetic men. Men with T2D have an increasingly greater risk of ED with increased duration since diagnosis (trend test $P$ value $<0.0001)(\mathrm{RR}=1.7,95 \%$ CI $1.1-2.7$, for men diagnosed $>20$ years previously) [31]. According to Vickers et al. the prevalence of ED is $32 \%$ in T1D and $46 \%$ in T2D [33].

Finally, a recent study performed in 499 patients with a new or recent diagnosis of T2D found mild ED in $19.4 \%$, mild to moderate ED in $15.4 \%$, moderate ED in $10.4 \%$ and severe $\mathrm{ED}$ in $21.6 \%$ [34].

\section{The role of cofactors in the pathophysiology of erectile dysfunction in patients with diabetes}

It is now clear that the prevalence of ED increases in men with diabetes. Pathological circumstances acting as co-factors closely associated with diabetes, such as obesity, hypertension and its pharmacological treatments, atherosclerosis, neuropathy, nephropathy, hypogonadism, infections, disease of penile structure and depression need to be investigated (Fig. 2).

\subsection{Glycaemic control}

Intensive glycaemic control reduces the development of erectile dysfunction [35]. Weinberg showed the highest rates of ED in diabetic patients with the poorest glycaemic control $(\mathrm{HbAlc}>7.5 \%)$ and the most severe insulin resistance (IR) [36]. Males with poor glycaemic control are at a two- to five fold increased risk of ED compared with patients whose disease is well controlled [32, 36], above all due to elevated $\mathrm{HbA1c}$ levels and the associated hyperglycaemia which decreases NO activity and reduces endothelium-dependent relaxation factors [37].

\subsection{Metabolic syndrome, obesity and hypogonadism}

Recent analyses of the causes of ED clarify the close link between insulin resistance, metabolic syndrome and the development of ED [38, 39]. In 2009 Hermans et al. [40] investigated ED in males with T2D using the IIEF questionnaire. This work underlined the association between ED and T2D and found a marked increase, in comparison with controls, in the probability of developing metabolic syndrome $(88 \%$ vs 
Fig. 2 Cofactors in the pathophysiology of erectile dysfunction in patients with diabetes

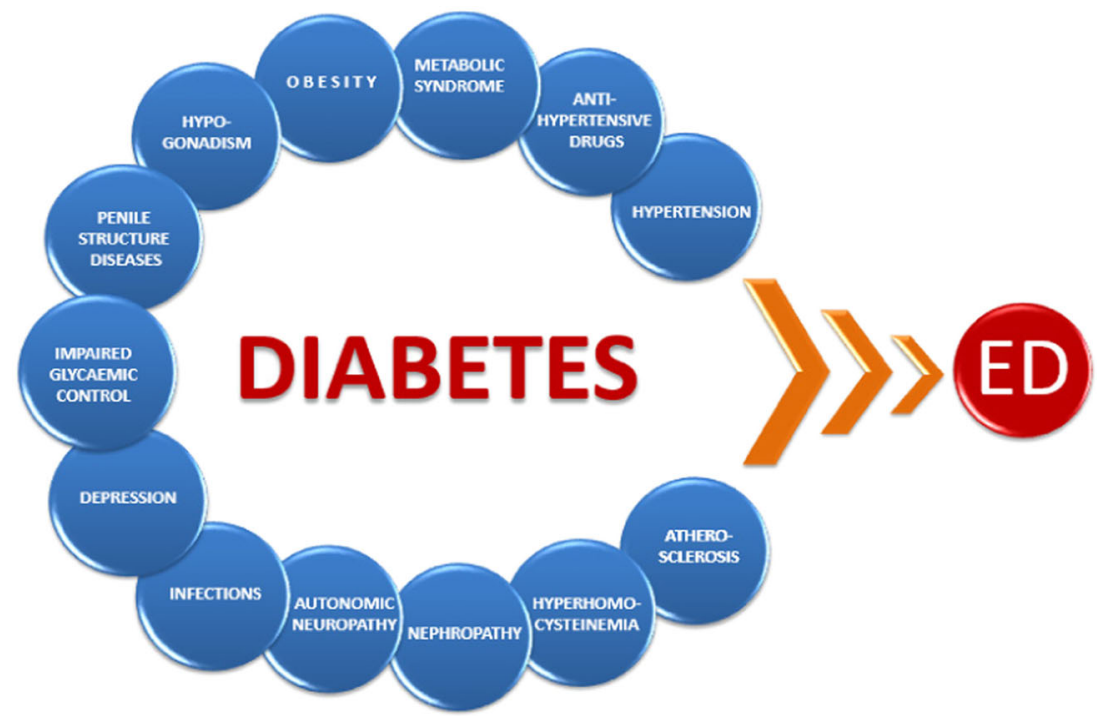

$64 \% ; P=0.002$ ), central adiposity and microangiopathy (retinopathy, polyneuropathy and increased albuminuria) [40]. Aslan et al. showed a significant association between T2D and severe ED, while the relative risk is as high as 7.1 $(P<0.001)$ in patients with metabolic syndrome [41].

Patients with ED and T2D have a higher prevalence of hypogonadism [42], and poor glycaemic control reduces testosterone levels, exacerbating ED [43]. The clinical relevance of this association was reported in a study by Kapoor et al. underlining the association of obesity with low testosterone levels [44]. The mechanism of hypogonadism in diabetes is to clarify. An important role could be played by a low plasma concentration of sex-hormone-binding globulin (SHBG), the most effective carrier of testosterone, as it is closely related to increased insulin resistance. Another possible mechanism could be aromatase hyperactivity in visceral adipose tissue leading to low testosterone concentration through the conversion of testosterone to oestradiol [28]. This drop in testosterone increases lipoprotein lipase activity, favouring the uptake of free fatty acids and proliferation of adipocytes, further increasing visceral adiposity [45]. Bruning et al. suggested that insulin resistance associated with T2D could cause reduced insulin activity in the hypothalamus, inducing a state of hypogonadotropic hypogonadism [46].

\subsection{Atherosclerosis and hyperhomocysteinaemia}

Atherosclerotic cardiovascular disease is an important complication in patients with diabetes [47].

The Multiple Risk Factor Intervention Trial (MRFIT) and the United Kingdom Prospective Diabetes Study (UKPDS) defined and underlined the link between cardiometabolic risk factors and the increased risk of cardiovascular events in patients with diabetes. Moreover, an increased prevalence of diabetes indirectly implicates an increasing coronary risk, especially when diabetes and coronary heart disease (CHD) share common risk factors [48]. It is therefore important to identify cardiometabolic risk factors in patients with diabetes.

Patients with diabetes also have a two- to fourfold increased risk of macrovascular disease compared with those without diabetes. One of the most frequent and chronic complications of diabetes is progression of coronary and peripheral vascular atherosclerosis [49]. Fukui et al. found a strong link between ED and atherosclerosis using the International Index of Erectile Function-5 score (IIEF) [50]. There is also a clear correlation between ED and diabetic micro- and macroangiopathy in patients with T2D [51].

One of the independent risk factors responsible for earlyonset atherosclerotic vascular disease is plasma total homocysteine [52]. Mild hyperhomocysteinaemia (HHcv) has various aetiologies, including insufficient intake of vitamins B6, B12 and folate, as well as genetic factors.

There is as yet no clear aetiological mechanism for $\mathrm{HHcv}$ but it may be related to increased vulnerability to lipid toxicity, vascular smooth-muscle-cell growth-factor properties of homocysteine, disorders of platelet aggregation and coagulation and endothelial damage or vasomotor dysfunction. An increase in homocysteine seems to be associated with ED in patients with T2D [53]. The mechanism underlying ED resulting from $\mathrm{HHcv}$ is also unclear but it could be related to increased vascular endothelial cell damage, reactive oxygen species (ROS) and atherosclerosis. Homocysteine could therefore be used as a new risk factor for ED and its measurement in plasma, alongside the measurement of folic acid levels and molecular analysis of the MTHFR genotype, might usefully be added to the ED diagnostic procedure [53]. 


\subsection{Autonomic neuropathy}

Autonomic neuropathy is a decrease or absence of the parasympathetic activity useful for relaxation of the smooth muscle of the corpora cavernosa, and is therefore strongly associated with ED [54, 55]. Debono et al. asserted that ED is an alert symptom for the future development of cardiac autonomous neuropathy [56], and it has been described as an independent cardiovascular risk factor [57, 58]. Peripheral neuropathy linked to diabetes leads to impairment of sensory impulses from the shaft and glans of the penis to the reflexogenic erectile centre. Motor neurons of the pudendal nerve innervate the pelvic floor muscles, inducing contraction of the bulbocavernous and ischiocavernosus muscles. This mechanism contributes to a reduction of venous outflow from the corpora cavernosa, preserving erection [28]. Bleustein et al. [59] underlined that in some cases of patients with diabetes, dysfunction of the penile nerves precedes neuropathy in other peripheral nerves.

\subsection{Hypertension and antihypertensive drugs}

In patients with diabetes hypertension is considered one of the most hazardous cardiovascular risk factors. It is often associated with ED [60]; however, some studies found that hypertension per se does not predispose men to ED [61]. Jensen et al. observed that in patients with hypertension, ED was mainly due to penile arterial vascular changes, probably atherosclerosis [62]. The number of risk factors, including criteria for metabolic syndrome (MS) and some traditional cardiovascular risk factors such as LDL levels, may also influence the severity of ED [63]. In this context, antihypertensive drugs could have an important impact on ED and thus on endothelium mediators. Whether this effect is positive or negative depends on the class used [64]. However, not all authors agree with this correlation [65].

In 2011 Baumhakel et al. conducted a systematic analysis of trials and concluded that only thiazide diuretics and beta blockers, not including nebivolol, may influence ED. Angiotensin receptor blockers, calcium channel antagonists and ACE inhibitors were reported to have no negative or even a positive effect on erectile function [66]. In the ONTARGET/ TRANSCEND trial performed by Böhm et al. in 1549 cardiovascular high risk patients, neither the ACE inhibitor ramipril, the angiotensin receptor blocker telmisartan, nor the combination of both had any positive effect on ED [67]. It seems therefore that no class of antihypertensive agents has an evident positive effect over other drugs in terms of quality of life, although ACE inhibitors, angiotensin II receptor antagonists and nebivolol may offer some advantages, at least on cognitive function and sexual activity [68]. Losartan seems to be effective and well tolerated in patients with $\mathrm{T} 2 \mathrm{D}$ and $\mathrm{ED}$, combined losartan and tadalafil therapy appears to be more effective than monotherapy [69]. A recent study suggests that felodipine-irbesartan may prevent oxidative stress [70].

\subsection{Nephropathy}

Diabetic nephropathy (DN) is characterised by excessive urine albumin excretion (albuminuria), diabetic glomerular lesions and reduced glomerular filtration rate (GFR) [71]. Its association with diabetes means that it has become the most frequent cause of end-stage renal disease in most countries, given the increasing prevalence of diabetes and the aging population. Overt nephropathy (persistent albuminuria of $\geq 300 \mathrm{mg} / 24 \mathrm{~h}$ ) develops after many years in T1D but could already be present at the time of diagnosis in T2D.

The pathophysiology of DN involves arteriolar resistance, presenting an increased glomerular hydrostatic pressure and hyperfiltration. The activation of the renin-angiotensin system and the development of proinflammatory and profibrotic molecules and high angiotensin converting enzyme (ACE) levels are associated with an increase in albuminuria [72]. Moreover, increased levels of endothelin-1 and urotensin II contribute to vasoconstriction and dysregulation of imbalance of nitric oxide and nitric oxide synthase, exacerbating DN. A recent study by Chuang et al. found that albuminuria is an independent risk factor for ED in men with diabetes after adjustment for age and duration of diabetes. The identification and control of albuminuria and other associated risk factors could therefore have an important role in the prevention or reversal of ED [73].

\subsection{Infections and penile structure diseases}

Infection-induced inflammation may be associated with endothelial dysfunction. Some infections associated with diabetes, such as chlamydia pneumoniae or cytomegalovirus, lead to low-grade inflammation. ED may also therefore be linked to these infections, due in part to elevated high-sensitivity Creactive protein and fibrinogen levels [74]. Another infection, balanitis, is closely associated with diabetes ( $16 \%$ vs $5.8 \%$ in the general population) [75]. The inflammation and related pain caused by balanitis could induce unfavourable psychological effects, impeding achievement of a satisfactory erection [21].

Some structural diseases of the penis could impair the physiology of erection in diabetes. Peyronie's disease (induratio penis plastica) is one of these. Its prevalence in diabetic men ranges from 8.1 to $18.3 \%[21,76,77]$, of whom $20.3 \%$ suffer from ED. Furthermore, diabetes may be associated with acquired phimosis. In a study by Bromage et al., $12 \%$ of men presenting with acquired phimosis and no history of diabetes were diagnosed with hyperglycaemic [78]. 


\subsection{Depression}

An increasingly important factor in the development of ED in men with diabetes is depression. In a study by De Berardis et al. in 1460 diabetic men, $24 \%$ presented severe and $34 \%$ mild-moderate ED [79]. Severe ED was mainly related to the severity of diabetes, while mild-moderate ED was independent of clinical variables and associated with the severity of depressive symptoms. Psychological factors are also often present in patients with diabetes, together with other comorbidities. Psychosexual counselling is therefore often an effective tool for men with ED and diabetes [80], and could be helpful as an adjunct to drug therapy.

\section{Treatment of erectile dysfunction}

A successful treatment of ED depends on its causes. The first line therapy are represented by PDE5 inhibitors (PDE5is). Penile self-injection with vasoactive drugs (alprostadil), vacuum erection devices and penile prostheses are other possibilities. The latter could be used in patients for whom PDE5is therapy or self-injection programs have failed or are not possible. In non-responders to PDE5i, vascular regenerative therapy involving mesenchymal stem cell or adipose tissue stem cell transplantation and endothelial nitric oxide synthase or vascular endothelial growth factor gene therapy [81] may be useful, and have been the subject of attention in various studies in recent years. It is also necessary to investigate any disease causing ED. In hypogonadic men [82], testosterone replacement therapy should be the initial treatment and could potentiate the effects of PDE5is in non-responders [83], while in overweight or obese patients, losing weight could be helpful [84]. The introduction of psychological intervention before and during pharmacological treatment could also be useful [85]. Today several PDE5is are available for treatment of ED.

\subsection{Sildenafil}

Sildenafil was the first effective oral treatment for ED. In 1999 , Rendell et al. demonstrated a $56 \%$ efficacy in improving erections in diabetic men [86] while approximately $50 \%$ of prostatectomised men with prostate cancer benefited [87] (less than in men with a nerve-sparing operation [88]. The T $1 / 2$ is approximately $4 \mathrm{~h}$ and the duration of action is about $8-12 \mathrm{~h}$ [89]. Onset of action is between 30 and $60 \mathrm{~min}$ [90]. Sildenafil also inhibits type 6 phosphodiesterase (PDE6i), which is important for the transformation of light into electrical signals. It could therefore affect the retina for a few hours, but it does not damage visual acuity or the visual field.

\subsection{Vardenafil}

Vardenafil is marketed as a film-coated tablet, with an oro dispersible tablet (ODT) formulation recently becoming available. Goldstein et al. demonstrated an improvement in erectile function with diabetes (452 patients with T1D or T2D [91]. Premature ejaculation in the absence of ED may also be improved $[46,92]$.

The T $1 / 2$ is approximately $4-5 \mathrm{~h}$ (maximum 6 for ODT formulation) and the duration of action is about $8-12 \mathrm{~h}$. Onset of action is within 20-30 $\mathrm{min}$ (15-25 min for ODT formulation) [90]. In 2003, the Food and Drug Administration's Cardiovascular and Renal Drugs Advisory Committee underlined that there may be a slight prolongation of the QT interval in patients using vardenafil, which therefore should not be used for patients with congenital QT prolongation or in men taking antiarrhythmic drugs such as procainamide, quinidine, sotalol or amiodarone [93].

\subsection{Tadalafil}

While sildenafil and vardenafil absorption depends on food (meals rich in fat) [90] or alcohol, tadalafil's absorption and pharmacodynamic properties are independent [94]. In 2013, Koka et al. demonstrated that body weight and fasting glucose levels in $\mathrm{db} / \mathrm{db}$ mice did not drop significantly after tadalafil administration, while insulin and triglyceride levels were significantly reduced compared to a group of untreated $\mathrm{db} / \mathrm{db}$ mice [95]. Daily administration for 28 days reduced infarct size in $\mathrm{db} / \mathrm{db}$ mice compared to untreated $\mathrm{db} / \mathrm{db}$ mice [95].

The $\mathrm{T} 1 / 2$ is approximately $17.5 \mathrm{~h}$ and the duration of action is about 24-36 h. The onset of action is 60-120 $\mathrm{min}$ [90]. Myalgia and back pain are two of the most common adverse events reported following tadalafil administration and the cause is thought to be mainly due to cross-reaction with PDE11 [96].

\subsection{Avanafil}

Avanafil is the last of the PDE5is currently approved worldwide. Its novelty lies in its rapid onset and its high selectivity for PDE1, PDE6 and PDE11. Avanafil was found to be efficacious in randomised, double-blind, placebo-controlled trials in men with $\mathrm{ED}[97,98]$ and in association with diabetes [98]. The $\mathrm{T} 1 / 2$ is approximately $3-5 \mathrm{~h}$ and duration of action is approximately $6 \mathrm{~h}$. Onset of action is within $15 \mathrm{~min}$ [90]. Avanafil is not indicated for use in patients with severe liver damage.

\subsection{Udenafil}

Udenafil is not yet approved worldwide [99]. Due to its $\mathrm{T}_{\max }$ of about $1-1.5 \mathrm{~h}$ and half-life of about $13 \mathrm{~h}$ [100], this new 
PDE5i could be ideal for daily use [90]. The T $1 / 2$ is approximately $11-13 \mathrm{~h}$ and the duration of action is about $24 \mathrm{~h}$. Onset of action is within $60 \mathrm{~min}$ [90]. It has also proven efficacious in patients with diabetes $[101,102]$. Clinical trials revealed that most adverse effects (of which the most common are headache and flushing) are mild or moderate, and there have been no serious adverse events reported [90, 103].

\subsection{Mirodenafil}

Preclinical studies revealed that mirodenafil's selectivity toward PDE5 is 10-fold higher than sildenafil, whereas its inhibitory effects on other PDEs are much lower than those of sildenafil.

In a meta-analysis Du W. et al. found that mirodenafil was more effective than placebo after 12 weeks' treatment, and its tolerability was good [104]. The T $1 / 2$ is approximately $2.5 \mathrm{~h}$ and the duration of action is about $6 \mathrm{~h}$. Onset of action is within 30-60 min [90]. Flushing and headache are common adverse events in patients using this PDE5i (mirodenafil versus placebo: $15.8 \%$ versus $3.2 \%$ and $3.1 \%$ versus $0 \%$ respectively) [104].

\section{Clinical trials in patients with diabetes and erectile dysfunction}

Several studies have found that response to pro-erectile drugs is lower in patients with diabetes than in non-diabetic subjects $[91,105]$. Furthermore, ED in diabetes is a progressive condition and none of these drugs has proved effective in arresting disease progression. For this reason, the first step in treating $\mathrm{ED}$ in diabetic patients is always to ensure adequate control of the risk factors known to affect disease aetiology, through changes in lifestyle, selection of concomitant medications and regular follow-up visits.

\subsection{Lifestyle modification, glycaemic control and other medications}

Emerging evidence shows that strict glycaemic control can improve endothelial dysfunction and testosterone levels [106], therefore acting on two putative mechanisms of the disease including vascular and hormonal factors. $\mathrm{Lu}$ et al. evaluated the correlation between glycaemic control and the risk of developing erectile dysfunction: $83.4 \%$ out of 792 diabetic men screened with the Sexual Health Inventory for Men questionnaire reported having ED, which was severe in $43 \%$. These authors found that the major risk factors for developing ED in diabetic men aged 60 years or under were poor glycaemic control, age and diabetes duration. For men over 60, the only independent risk factor for ED turned out to be age [107]. These data seem to suggest that early glycaemic control in young males is required to prevent subsequent $\mathrm{ED}$ later in life. A meta-analysis of six clinical trials investigating the effect of lifestyle changes to reduce cardiovascular risk in diabetes also found a statistically significant improvement in sexual function when measured by IIEF score [108]. A limitation of most of these studies was that they were not designed to test the hypothesis that ED would improve with this kind of intervention, nevertheless the results appear promising. In the AHEAD trial, the effect of weight control was investigated in elderly, overweight and obese diabetic men. The authors concluded that weight loss was moderately helpful in preserving erectile function [109]. Weight loss could also improve ED through other mechanisms: reduced inflammation, increased testosterone levels due to less aromatisation or improved Leydig cell function [110], and a better mood and self-esteem. Strong evidence of the benefits that lifestyle intervention can exert on ED is provided by the randomised, controlled study conducted by Esposito et al. on 110 obese men, where 24 months of controlled food intake and increased physical activity restored erectile function in $31 \%$ of subjects allocated to the Mediterranean diet [111]. Lifestyle interventions and endothelial cell protection are advised in diabetic subjects, however, they require a long time to become effective, and PDE5is remains the first-line therapy to control symptomatic ED (Table 1).

\subsection{PDE5 inhibitors}

Since the release of sildenafil, PDE5is have quickly become the first-line therapy for ED, due to their efficacy and excellent compliance (Table 2). A large number of clinical trials have demonstrated the effectiveness of PDE5is in improving ED in diabetes, and they have been found to be generally safe and well tolerated. However, a high failure rate is reported if concomitant psychosexual, relational and social factors are ignored. A Cochrane Review published in 2007 showed that PDE5is improve ED in diabetic men [112]. Nevertheless, several clinical trials found that the response to all PDE5is is lower than in non-diabetics (Table 3) [113, 114]. In a systematic review comparing 936 diabetic against 1301 non-diabetic men taking different PDE5is treatments (sildenafil, tadalafil, vardenafil), response in terms of improvement in all questionnaires (IIEF, SEP, Global Efficacy) was lower in diabetic patients [115]. All these three major PDE5is have been evaluated for ED in diabetic patients and shown to have similar levels of effectiveness. Of the very few non-sponsored comparative studies, the ENDO-trial [116] revealed a substantial equivalency in clinical response to all drugs, with a slightly higher colour-Doppler vascular response obtained with high doses of sildenafil. Sildenafil has been widely studied in diabetic patients with ED. Response rates range from 52 to $66 \%$ and side effects are generally reported as mild to moderate [86, 117-119]. Vardenafil has also been extensively investigated 
Table 1 Lifestyle changes and pharmacological treatments

\begin{tabular}{|c|c|c|c|c|c|c|c|}
\hline Author & Type & $\begin{array}{l}\text { No. of } \\
\text { patients }\end{array}$ & Disease & $\begin{array}{l}\text { Age - } \\
\text { mean/range }\end{array}$ & Intervention & $\begin{array}{l}\text { Methodologies } \\
\text { and scale }\end{array}$ & Results \\
\hline Gupta et al. & Meta-analysis & 740 & $\mathrm{~T} 2 \mathrm{D}$ & 55.4 & $\begin{array}{l}\text { Lifestyle changes and } \\
\text { cardiovascular risk } \\
\text { factor reduction }\end{array}$ & IIEF & $\begin{array}{l}\text { IIEF score improved } \\
\text { by } 2.66 \text { on IIEF }\end{array}$ \\
\hline Esposito $\mathrm{K}$ et al. & DB PC RCT & 110 & Obesity & $35-55$ & $>10 \%$ weight loss & IIEF & $\begin{array}{l}\text { IIEF score improved } \\
\text { from } 13.9 \pm 4.0 \\
\text { to } 17 \pm 5\end{array}$ \\
\hline Caro et al. & DB PC RCT & 82 & Hypertension & $30-65$ & Losartan $50-100 \mathrm{mg}$ & $\begin{array}{l}\text { Self-administered } \\
\text { questionnaire }\end{array}$ & $\begin{array}{l}\text { Improved sexual } \\
\text { satisfaction from } \\
\text { an initial } 7.3 \\
\text { to } 11.6(58.5 \%)\end{array}$ \\
\hline
\end{tabular}

$T 2 D$ type 2 diabetes, $D B$ double blind, $P C$ placebo controlled, $R C T$ randomised controlled trial, IIEF International Index of Erectile Function

in diabetic subjects $[120,121]$. Specifically, in a multicentre, double-blind placebo-controlled, fixed-dose trial with 452 patients with T1D and T2D, vardenafil produced better erections in $57 \%$ and in $72 \%$ of patients allocated to $10 \mathrm{mg}$ or $20 \mathrm{mg}$, respectively, compared to $13 \%$ in the placebo arm [91]. Finally, the long-acting PDE5i tadalafil has proven to be safe and effective for diabetic patients with ED [122]. The average increase in IIEF score was 7.4 points for patients taking the higher $20 \mathrm{mg}$ dose as needed, against a 0.9 point rise with placebo [114]. In general, diabetic patients are less responsive to PDE5is drugs. For this reason, regardless of which PDE5i is chosen, they are best treated with the highest available dose, Subsequent dose titration is always possible, but a first attempt failure with a low-dose approach often jeopardises patients' confidence in the possibility of regaining successful sexual relations. There have been some recent novelties in the treatment of diabetes-related ED. First, three new PDE5is, avanafil, udenafil and mirodenafil, have reached the market, and are all being tested in diabetic patients [98, 101]. Second, daily administration, as opposed to traditional on-demand or twice-weekly use, has been tested for tadalafil and sildenafil. Daily tadalafil is currently FDA- and EMA-approved for the treatment of ED and lower urinary tract symptoms. The latter indication is of particular interest, as it is a frequent complication in patients with diabetes [123]. Of these new PDE5is, avanafil, which was approved in early 2012, appears to be the most rapidly absorbed, and is highly selective [124]. Its efficacy in diabetic men was recently evaluated in a randomised, double-blind, placebo-controlled trial: 390 diabetic men were randomised to receive avanafil $100 \mathrm{mg}$ or $200 \mathrm{mg}$ or placebo for 12 weeks. At the end of the study, there was a significant improvement in both groups treated with avanafil, as measured by number of successful sexual attempts and change in IIEF score. The mean IIEF changes were 4.5 and 5.4 points respectively in the 100 and $200 \mathrm{mg}$ avanafil groups. The safety profile was similar to other PDE5is [98]. Clinicians can also choose to prescribe PDE5is on a daily regimen scheme. While on-demand administration remains the first-line and most widely used approach, daily administration is a valuable alternative as it has been claimed to be more effective in reverting endothelial dysfunction, the hallmark in the pathogenesis of ED in diabetes. Dosages as low as 2.5 or $5 \mathrm{mg}$ per day have been found effective in diabetic patients. In a recent trial, 280 diabetic men with ED were randomised to tadalafil $2.5 \mathrm{mg}$ or $5 \mathrm{mg}$ or placebo for 12 weeks; in clinical practice even the $2.5 \mathrm{mg}$ daily dose seems to work well in non-complicated patients. This study found no difference in the rate of adverse events (4.0 and $3.1 \%$ for the 2.5 and $5 \mathrm{mg}$ groups, respectively), which were all mild in severity [123].

\subsection{PDE5 inhibitors and testosterone replacement therapy}

Despite these advancements, $30-50 \%$ of ED subjects fail to respond to PDE5is, lifestyle intervention or counselling (Table 4). The severity of ED due to advanced end-organ damage in the diabetic population leads many patients to seek alternative treatments. Low serum testosterone may be a contributing factor to ED in non-responders to PDE5is, so it is advisable to measure total and free testosterone levels, especially if there are also other signs or symptoms of hypogonadism. Metabolic impairment frequently accelerates androgen decline [110]. For patients with ED and concomitant hypogonadism, testosterone replacement therapy (TRT) is an effective treatment. TRT is only recommended for patients with proven biochemical hypogonadism, with total testosterone levels $\leq 12 \mathrm{nmol} / \mathrm{L}$ [82]. A double-blind, placebocontrolled trial of long-acting testosterone undecanoate in diabetic men with total testosterone $<12 \mathrm{nmol} / \mathrm{L}$ or free testosterone $<250 \mathrm{pmol} / \mathrm{L}$ found a significant improvement in ED, satisfaction, sexual desire and orgasm. The improvements were observed starting at six weeks and continued up to 18 months. There were no adverse events [125]. Another prospective, randomised, double-blind, placebo-controlled trial 


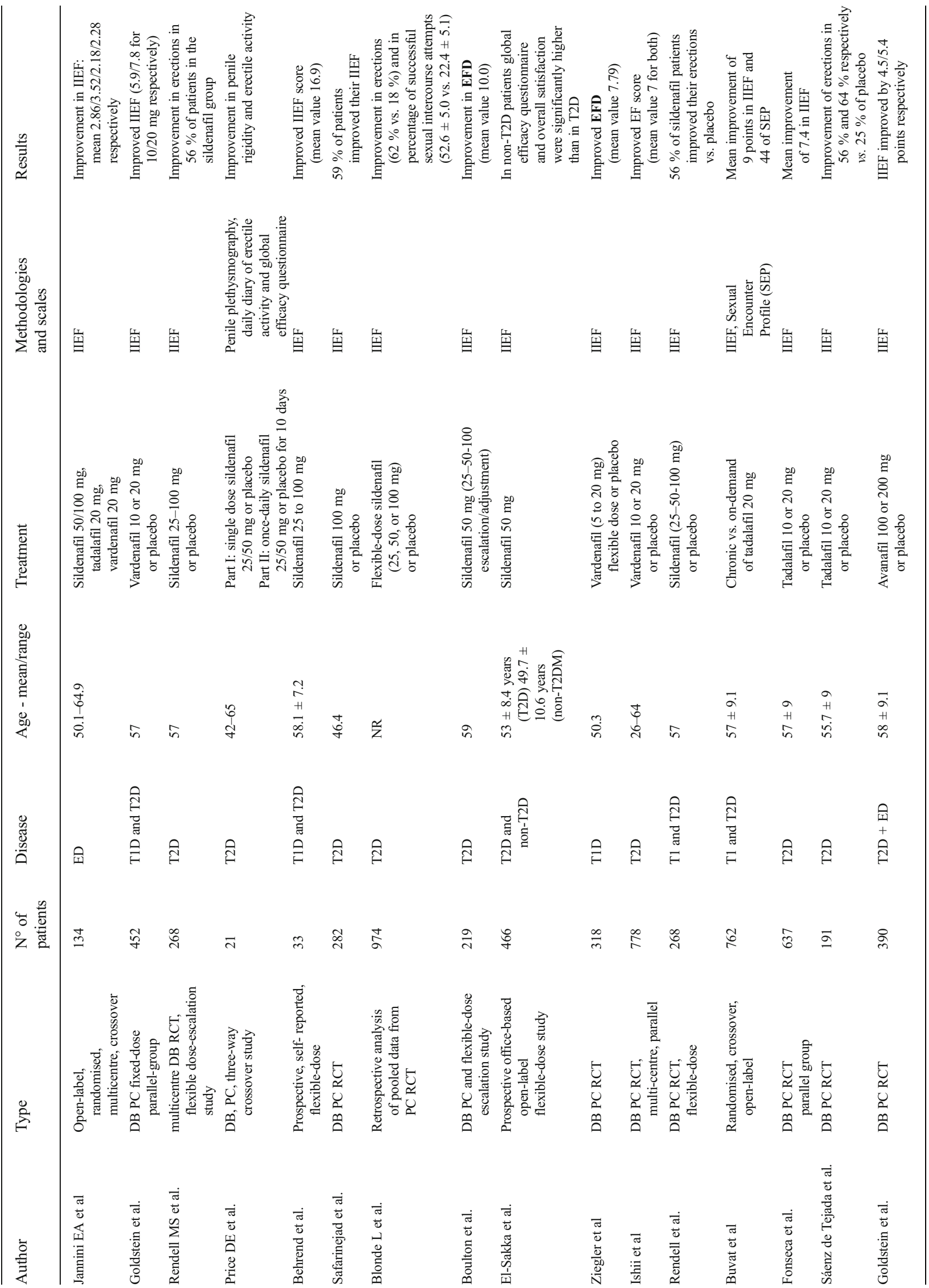




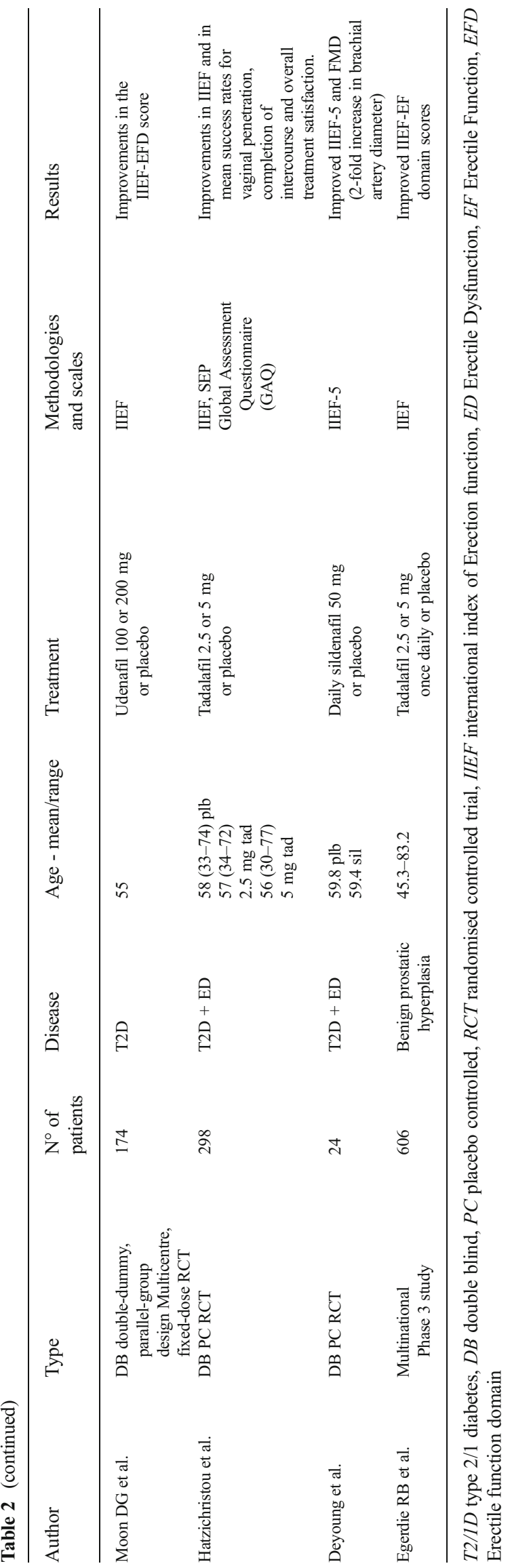

evaluated the transdermal administration of testosterone $2 \%$ gel in hypogonadal men with diabetes or metabolic syndrome. This trial found not only significant amelioration in sexual health based on the IIEF score but also improvement in insulin resistance and lipid levels [126]. Combined therapy with PDE5is and testosterone has been the subject of recent controversies. Whether androgens should be started before or after PDE5is treatment [127] was questioned in 2012 by Spitzer et al., who showed that PDE5is alone can restore eugonadism in a significant proportion of hypogonadal men by improving sexual frequency or possibly by acting directly on Leydig cells [128]. Furthermore, in 2011 an interesting piece of work of Buvat et al. in the TADTEST study showed that the maximal beneficial effects of once a day tadalafil $10 \mathrm{mg}$ may occur only after as many as 12 weeks; adding testosterone to this type of PDE5i could be beneficial, but only in hypogonadal men with baseline testosterone levels $\leq 3 \mathrm{ng} / \mathrm{mL}$ [129]. However, this has not been proven in diabetic subjects, and the expected delta increase in total testosterone is in the order of 2 to $4 \mathrm{nmol} / \mathrm{L}$. Severe hypogonadal subjects are therefore unlikely to respond and would be advisable to be treated with the combined therapy (PDE5i + testosterone). It is worth noting that androgens can improve several outcomes other than ED in diabetic patients, therefore the risk-benefit analysis should be carried out considering all these aspects [130]. However, the cardiovascular safety of androgens in elderly subjects is still under debate [131].

\subsection{Other treatments for ED in diabetes}

For those who still do not respond effectively to medical treatment, whether monotherapy or combined, second-line therapies should be considered. One option is the use of minimally invasive intra-urethral vasoactive substances, although their efficacy in clinical practice does not reflect the efficacy observed in trials. The most popular agent is alprostadil (PGE1) used in an urethral suppository first marketed as MUSE (Medicated Urethral System for Erection). MUSE comes in the form of a pellet suspended in polyethylene glycol and is administered with an applicator. The vasoactive agent is absorbed through the urethra (about $80 \%$ in $10 \mathrm{~min}$ ) and facilitates erection. Although initial trials showed good efficacy, with an intercourse success rate approaching $51.2 \%[132$, 133], its use has declined in the last 10 years as it did not prove to be as effective in clinical practice. However, the role of topical alprostadil is now being reconsidered, especially in the treatment of ED in diabetic patients for whom oral PDE5 is therapy is ineffective. Recent phase III trials produced positive results leading to the approval of topical alprostadil in Canada [134]. A recent review confirmed intraurethral alprostadil to be an effective second-line treatment with higher acceptance and compliance rates than other treatments. Although it is less effective than intracavernous PGE1 
injections, its easy administration via the dedicated applicator and the lack of any injection-related issues (needle/pain/difficulty) [135] justify its place among second-line therapies in diabetes. Intracavernosal injection is the oldest and still one of the most effective treatments for ED in diabetic patients. The intracavernous injection of $10 \mathrm{mg}$ of PGE1 has been shown to restore valid erections in $55.5 \%$ of diabetic men with $\mathrm{ED}$, compared to a complete lack of response in the placebo group [136]. Diabetic men, especially those under insulin therapy, are more familiar with injection therapy and accept intracavernous PGE more easily than non-diabetic men. Some authors have also shown that the use of intracavernosal injections is safe and effective in the long run, but emphasised the importance of close follow-up of diabetic patients to reduce non compliance, as the number of self-injections inevitably increases over the patient's lifetime [137]. Coombs et al. feared complications of intracorporeal injections such as priapism, but found the incidence to be as low as $0.5 \%$ when close at-home monitoring is encouraged [138]. Penile fibrosis and La Peyroinie disease have also occasionally been reported in association with PGE1 injections, however, no controlled data are available. Among less-studied approaches, vacuum erection devices (vEDS) have often been proposed although for many patients these devices are heavy and uncomfortable to use. In a clinical trial vacuum devices were tested in 162 patients with diabetes who were non-responders to sildenafil or had contraindications to PDE5is use. Of these, 114 (70.4\%) showed a positive response and $8 \%$ complained of pain. However, only $19(11.7 \%)$ agreed to continue using the device outside the trial, and 12 (63\%) of these subsequently switched to other treatments, mainly complaining of a cold penis and pain [117]. It is likely that patient counselling and support during the trial influenced the high acceptance/ success rate of the device. A variety of surgical revascularisation techniques have been described in the scientific literature. However, because of the difficulty and invasiveness of these procedures, as well as the observation that ED affects microvascular homeostasis, it is unlikely that such techniques can produce long-lasting results and they cannot yet be considered viable treatment options. The implantation of a penile prosthesis is the most attractive surgical option for men for whom all other ED treatments were ineffective. The safety and efficacy of these devices have been amply demonstrated, with sufficiently low infection rates and durable longterm effectiveness even in high-risk diabetic patients.

\section{Novel indications for use of PDE5 inhibitors in patients with diabetes}

In recent years, great interest has arisen around some novel clinical indications for PDE5is in diabetes including treatment 


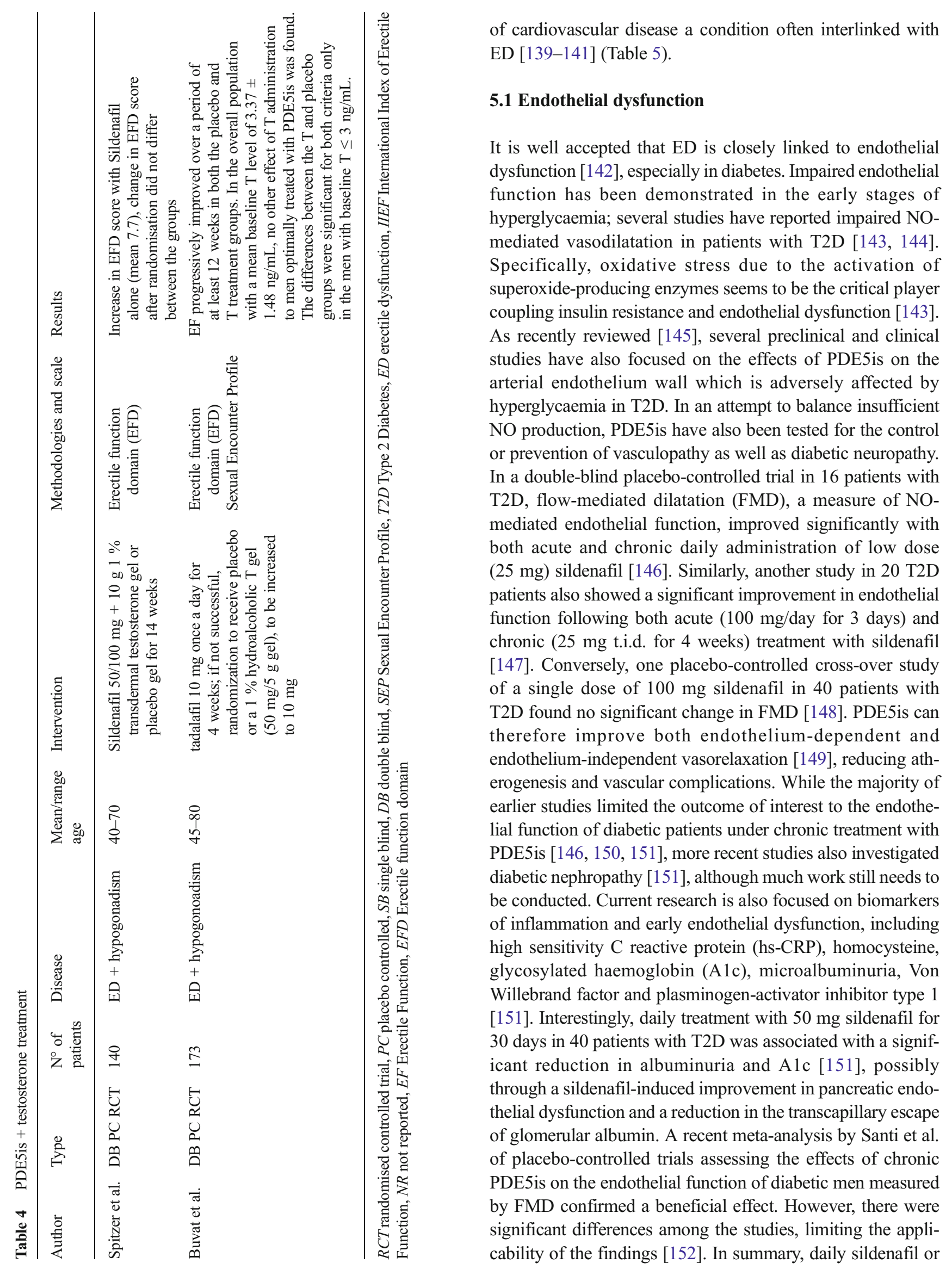




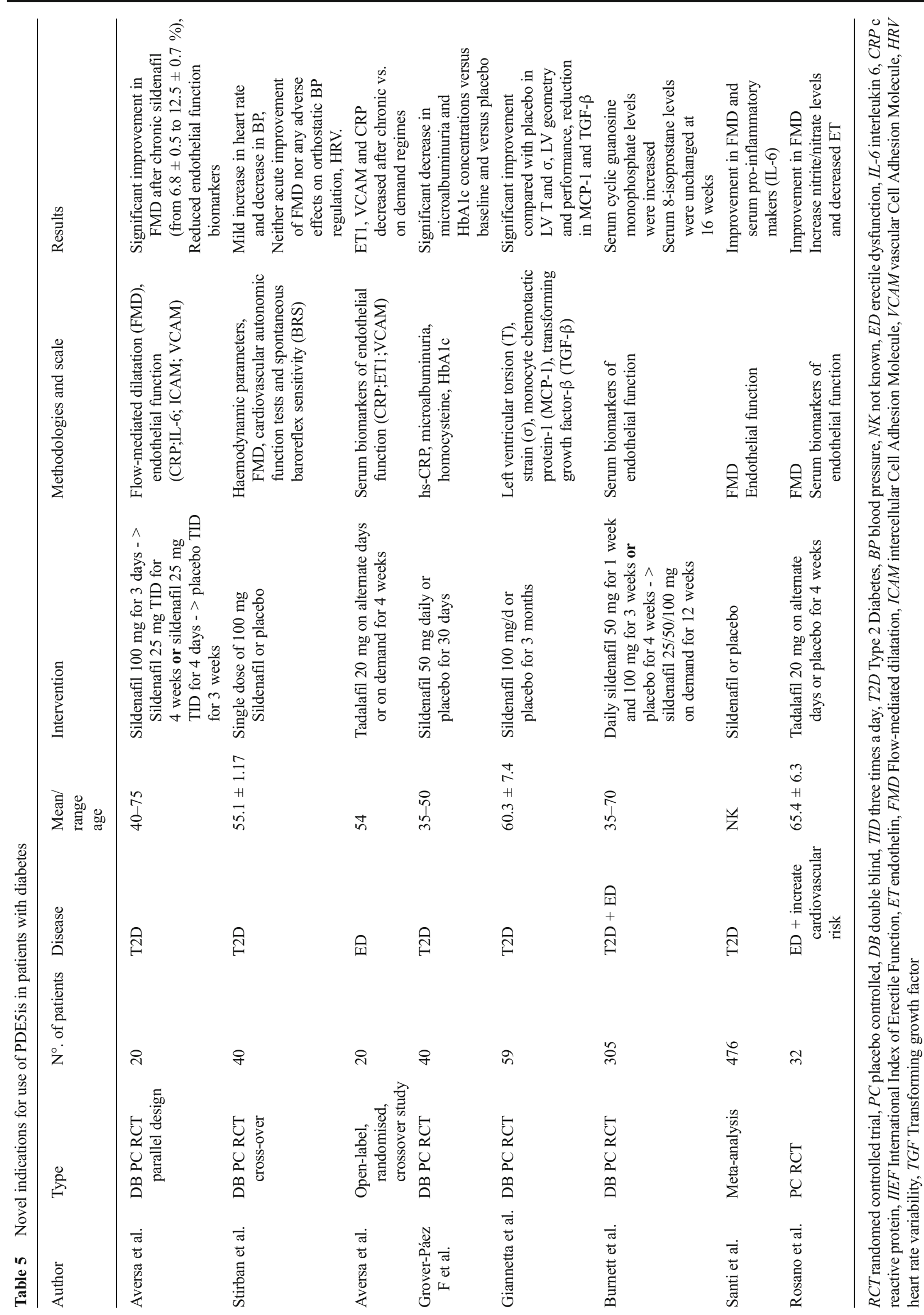


tadalafil treatment seem to exert prolonged beneficial effects on endothelial cell metabolism in patients with T2D [146], which can last for more than 2 weeks after discontinuation of treatment [153].

\subsection{Diabetic heart and pro-inflammatory state}

The normal myocardium expresses minimal or no PDE5. However, PDE5 expression increases in a number of myocardial diseases, including cardiomyopathies and ventricular hypertrophy. The diabetic myocardium is especially vulnerable to ischaemia/reperfusion ( $\mathrm{I} / \mathrm{R}$ ) injury [154]. Restoration of blood flow to previously ischaemic tissue can trigger arhythmia, endothelial damage, myocardial stunning, myocyte death and reinfarction. Great effort has been made to develop cardioprotective strategies such as pre- and postconditioning [155]. It was recently shown that chronic tadalafil significantly reduces infarct size in T2D hearts [95, 156]. Despite growing evidence from animal studies, no clinical trial has found any role for PDE5is against ischaemia/ reperfusion injury. Kukreja et al. [157] suggested that the administration of high doses of PDE5is after myocardial infarction or cardiac arrest reduces heart muscle loss and improves survival. A retrospective cohort study evaluated cardiovascular risk in over 5000 sildenafil users in England [158]. Complications from ischaemic heart disease were $30.1 \%$ lower than those in a matched population of non-users, suggesting some protection from age-adjusted mortality. PDE5is have also been tested for cardiac remodelling and heart failure. Diabetes is associated with a progressive adaptive change in myocardial tissue, known as diabetic cardiomyopathy, that occurs independently of ischaemia or hypertension. Concentric remodelling in diabetes is the result of neuro-hormonal, inflammatory and pro-fibrotic triggers. Diabetic cardiomyopathy may also involve eccentric remodelling as a response to volume overload and to severe diastolic dysfunction, leading to chamber dilatation. These changes forego heart failure [159], which is twice as common in diabetic subjects as in the general age-matched population. The antihypertrophic and anti-apoptotic effects of PDE5 inhibition are well described in animal models [157]. The general mechanism is thought to be via cGMP/PKG activation, although more recent data suggest that alternative signalling may act in cardiomyocytes. The effects of short- and long-term PDE5is administration seem to differ according to the stressor involved and the rapidity of onset. Lindman et al. explored the short-term haemodynamic effects of a single PDE5i dose in non-diabetic patients with severe aortic stenosis. Guazzi et al. provided the first evidence of PDE5i-reversed remodelling in humans with heart failure [160], while Giannetta and colleagues reported their anti-remodelling role in T2D. These results were independent of afterload and were not seen after short-term sildenafil administration, suggesting a direct structural effect on cardiomyocytes opposing the maladaptive changes triggered by metabolic dysfunction. These authors found that the improved LV function was associated with a reduction in monocyte chemotactic protein-1 [MCP1], a potential new biomarker apparently associated with heart disease progression [140]. Current research is exploring other possible intramyocardiocyte signalling pathways to explain some of the PKG-independent effects activated by PDE5 inhibition. In $\mathrm{T} 2 \mathrm{D}$, the myocardium is exposed to intense oxidative stress. Chronic treatment with tadalafil caused significant suppression of ROS production, cardiac NADPH oxidase activity, lipid peroxidation and oxidised glutathione [95]. Interestingly, tadalafil seems to attenuate the myocardial response of specific subunits of NADPH oxidase enzyme, suggesting a specific protection against excessive ROS generation. Last but not least, hyperglycaemia is associated with greater systemic inflammation [161]. The results of the previously cited meta-analysis by Santi et al. confirmed that in men too, chronically administered PDE5is lead to a partial reduction in pro-inflammatory cytokines, including IL-6. However, they also showed that several other pro-inflammatory cytokines did not respond to PDE5is, and a reproducible, validated serum marker of endothelial function reproducibly affected by PDE5is has not yet been identified [152]. Taken together, the preclinical and human studies clearly indicate that PDE5is could target several cardiac, inflammatory and vascular dysfunctions triggered by the metabolic impairment. However, the mechanisms involved are far from being clarified and more studies are warranted in light of the promising preliminary clinical results [140].

\section{Conclusions}

Hyperglycaemia damages tissues through many different mechanisms. As the disease advances, tissue and vascular damage lead to severe complications which may be classified as both microangiopathic and macroangiopathic.

Several studies have demonstrated an increased incidence of ED in patients with diabetes, although almost none of them distinguished between T1D and T2D. However, those studies that did differentiate between the two found a similar prevalence of ED in both groups after adjusting for age [29, 31]. In diabetic men, the severity of ED increases with age, duration of diabetes, poor glycaemic control and presence of microvascular complications. Men with T1D and T2D are at a significantly higher risk for ED than non-diabetic men. Men with T2D have an increasingly greater risk of ED with increased duration since diagnosis. All pathological circumstances closely associated with diabetes such as obesity, hypertension and its pharmacological treatments, atherosclerosis, hyperhomocysteinaemia, neuropathy, nephropathy, hypogonadism 
and depression, need to be investigated when a diabetic patient presents with ED.

Of the currently available PDE5is, some are approved and marketed worldwide (sildenafil, vardenafil, tadalafil, avanafil) and others only in some countries (udenafil and mirodenafil). They differ in terms of the available doses, $\mathrm{T}_{1 / 2}$ and $\mathrm{T}_{\max }$, onset and duration of action and adverse effects, and above all on their selectivity profiles on different PDE5s. Past and current clinical trials in patients with T1D and T2D suggest numerous ways in which they can help in treating ED. In diabetic patients most attention has been paid to the analysis of cardiovascular risk factors, while also evaluating the concomitant comorbidity of hypogonadism. There are some indications for the use of PDE5is in patients with diabetes in whom they could be used to treat also endothelial dysfunction, diabetic heart and pro-inflammatory state.

There is no doubt about the need for both new medications and new studies, above all in non-responders to lifestyle changes and traditional treatments and to investigate cardiovascular prevention in diabetes. Ideally, this would enable the design of a tailor-made treatment for each patient.

\section{Compliance with ethical standards}

Conflict of interests GD: has received travel grant from Menarini, Ibsa; DG: nothing to declare;

CDE: nothing to declare;

RP: nothing to declare;

Lilly;

DT: has received a travel grant from Takeda, Menarini, Bayer, Eli

AP: has received honoraria from Eli Lilly and Sanofi Aventis;

$\mathrm{AL}$ : has received honoraria and travel grants from Eli-Lilly, Pfizer, Menarini, Bayer;

PP: has received honoraria, travel grants and speaker fees from Lilly, Sanofi, Astra Zeneca and Takeda.

No other potential conflicts of interest related to this article are reported.

\section{References}

1. Gratzke C, Angulo J, Chitaley K, Dai Y-T, Kim NN, Paick J-S, et al. Anatomy, physiology, and pathophysiology of erectile dysfunction. J Sex Med. 2010;7:445-75.

2. Sattar AA, Salpigides G, Vanderhaeghen JJ, Schulman CC, Wespes E. Cavernous oxygen tension and smooth muscle fibers: relation and function. J Urol. 1995; 154:1736-9.

3. Ayta IA, McKinlay JB, Krane RJ. The likely worldwide increase in erectile dysfunction between 1995 and 2025 and some possible policy consequences. BJU Int. 1999;84:50-6.

4. Nunes KP, Webb RC. No Title. ISBN 978-953-51-0199-4, InTech, 2012.

5. Leite R, Giachini FRC, Carneiro FS, Nunes KP, Tostes RC, Webb RC. Targets for the treatment of erectile dysfunction: is NO/cGMP still the answer? Recent Pat Cardiovasc Drug Discov. 2007;2:11932.
6. Bredt DS, Snyder SH. Isolation of nitric oxide synthetase, a calmodulin-requiring enzyme. Proc Natl Acad Sci U S A. 1990;87:682-5.

7. Sáenz de Tejada I, Angulo J, Cellek S, González-Cadavid N, Heaton J, Pickard R, et al. Physiology of erectile function. J Sex Med. 2004;1:254-65.

8. Andersson K-E. Mechanisms of penile erection and basis for pharmacological treatment of erectile dysfunction. Pharmacol Rev. 2011;63:811-59.

9. Andersson KE. Pharmacology of penile erection. Pharmacol Rev. 2001;53:417-50.

10. Granchi S, Vannelli GB, Vignozzi L, Crescioli C, Ferruzzi P, Mancina R, et al. Expression and regulation of endothelin-1 and its receptors in human penile smooth muscle cells. Mol Hum Reprod. 2002;8:1053-64.

11. Wingard CJ, Husain S, Williams J, James S. RhoA-Rho kinase mediates synergistic ET-1 and phenylephrine contraction of rat corpus cavernosum. Am J Physiol Regul Integr Comp Physiol. 2003;285:R1145-52.

12. Jin L, Burnett AL. RhoA/Rho-kinase in erectile tissue: mechanisms of disease and therapeutic insights. Clin Sci (Lond). 2006;110:153-65.

13. Siddiqui MA, Peng B, Shanmugam N, Yeo W, Fook-Chong S, Li Tat JC, et al. Erectile dysfunction in young surgically treated patients with lumbar spine disease: a prospective follow-up study. Spine (Phila Pa 1976). 2012;37:797-801.

14. Shamloul R, Ghanem H. Erectile dysfunction. Lancet. 2013;381: 153-65.

15. Sansone A, Romanelli F, Gianfrilli D, Lenzi A. Endocrine evaluation of erectile dysfunction. Endocrine. 2014;46:423-30.

16. Maseroli E, Corona G, Rastrelli G, Lotti F, Cipriani S, Forti G, et al. Prevalence of endocrine and metabolic disorders in subjects with erectile dysfunction: a comparative study. J Sex Med. 2015.

17. Aversa A, Rossi F, Francomano D, Bruzziches R, Bertone C, Santiemma V, et al. Early endothelial dysfunction as a marker of vasculogenic erectile dysfunction in young habitual cannabis users. Int J Impot Res. 2008;20:566-73.

18. Carson C, Dean J, Wylie M. Management of erectile dysfunction in clinical practice. New York: Springer Medical Publishing; 2006.

19. Stadler K Oxidative stress in diabetes. Adv Exp Med Biol. 2012;771:272-87.

20. Napoli N, Strollo R, Paladini A, Briganti SI, Pozzilli P, Epstein S. The alliance of mesenchymal stem cells, bone, and diabetes. Int J Endocrinol. 2014;2014:690783. doi:10.1155/2014/690783.

21. Kamenov ZA. A comprehensive review of erectile dysfunction in men with diabetes. Exp Clin Endocrinol Diabetes. 2014;123(3): 141-58.

22. Creager MA, Lüscher TF, Cosentino F, Beckman JA. Diabetes and vascular disease: pathophysiology, clinical consequences, and medical therapy: part I. Circulation. 2003;108:1527-32.

23. Kamenov Z, Christov VYT. Erectile dysfunction in diabetic menlinked more to microangiopathic complications and neuropathy than to macroangiopathic disturbances. J Men's Heal Gend. 2007;4:64-73.

24. Lewis RW, Fugl-Meyer KS, Corona G, Hayes RD, Laumann EO, Moreira ED, et al. Definitions/epidemiology/risk factors for sexual dysfunction. J Sex Med. 2010;7:1598-607.

25. Nicolosi A, Moreira ED, Shirai M, Bin Mohd Tambi MI, Glasser DB. Epidemiology of erectile dysfunction in four countries: crossnational study of the prevalence and correlates of erectile dysfunction. Urology. 2003;61:201-6.

26. Johannes CB, Araujo AB, Feldman HA, Derby CA, Kleinman KP, McKinlay JB. Incidence of erectile dysfunction in men 40 to 69 years old: longitudinal results from the Massachusetts male aging study. J Urol. 2000;163:460-3. 
27. Bacon CG, Mittleman MA, Kawachi I, Giovannucci E, Glasser DB, Rimm EB. Sexual function in men older than 50 years of age: results from the health professionals follow-up study. Ann Intern Med. 2003;139:161-8.

28. Phé V, Rouprêt M. Erectile dysfunction and diabetes: a review of the current evidence-based medicine and a synthesis of the main available therapies. Diabetes Metab. 2012;38:1-13.

29. Kalter-Leibovici O, Wainstein J, Ziv A, Harman-Bohem I, Murad H, Raz I. Clinical, socioeconomic, and lifestyle parameters associated with erectile dysfunction among diabetic men. Diabetes Care. 2005;28:1739-44

30. De Berardis G, Franciosi M, Belfiglio M, Di Nardo B, Greenfield S, Kaplan SH, et al. Erectile dysfunction and quality of life in type 2 diabetic patients: a serious problem too often overlooked. Diabetes Care. 2002;25:284-91.

31. Bacon CG, Hu FB, Giovannucci E, Glasser DB, Mittleman MA, Rimm EB. Association of type and duration of diabetes with erectile dysfunction in a large cohort of men. Diabetes Care. 2002;25: 1458-63.

32. Fedele D, Coscelli C, Santeusanio F, Bortolotti A, Chatenoud L, Colli E, et al. Erectile dysfunction in diabetic subjects in Italy. Gruppo Italiano Studio Deficit Erettile nei Diabetici. Diabetes Care. 1998;21:1973-7.

33. Vickers MA, Wright EA. Erectile dysfunction in the patient with diabetes mellitus. Am J Manag Care. 2004;10:S3-11 quiz S12-6.

34. Corona G, Giorda CB, Cucinotta D, Guida P, Nada E. Sexual dysfunction at the onset of type 2 diabetes: the interplay of depression, hormonal and cardiovascular factors. J Sex Med. 2014;11: 2065-73.

35. Wessells H, Penson DF, Cleary P, Rutledge BN, Lachin JM, McVary KT, et al. Effect of intensive glycemic therapy on erectile function in men with type 1 diabetes. J Urol. 2011;185:1828-34.

36. Klein R, Klein BEK, Moss SE. Ten-year incidence of self-reported erectile dysfunction in people with long-term type 1 diabetes. J Diabetes Complicat. 2005;19:35-41.

37. Al-Hunayan A, Al-Mutar M, Kehinde EO, Thalib L, Al-Ghorory $M$. The prevalence and predictors of erectile dysfunction in men with newly diagnosed with type 2 diabetes mellitus. BJU Int. 2007;99:130-4.

38. Esposito K, Giugliano F, Martedì E, Feola G, Marfella R, D'Armiento M, et al. High proportions of erectile dysfunction in men with the metabolic syndrome. Diabetes Care. 2005;28:12013.

39. Kaya E, Sikka SC, Gur S. A comprehensive review of metabolic syndrome affecting erectile dysfunction. J Sex Med. 2015;12(4): 856-75.

40. Hermans MP, Ahn SA, Rousseau MF. Erectile dysfunction, microangiopathy and UKPDS risk in type 2 diabetes. Diabetes Metab. 2009;35:484-9.

41. Aslan Y, Sezgin T, Tuncel A, Tekdogan UY, Guler S, Atan A. Is type 2 diabetes mellitus a cause of severe erectile dysfunction in patients with metabolic syndrome? Urology. 2009;74:561-4. doi: 10.1016/j.urology.2009.02.073.

42. Corona G, Mannucci E, Petrone L, Ricca V, Balercia G, Mansani $\mathrm{R}$, et al. Association of hypogonadism and type II diabetes in men attending an outpatient erectile dysfunction clinic. Int J Impot Res. 2006;18:190-7.

43. El-Sakka AI, Sayed HM, Tayeb KA. Type 2 diabetes-associated androgen alteration in patients with erectile dysfunction. Int $\mathrm{J}$ Androl. 2008;31:602-8.

44. Kapoor D, Aldred H, Clark S, Channer KS, Jones TH. Clinical and biochemical assessment of hypogonadism in men with type 2 diabetes: correlations with bioavailable testosterone and visceral adiposity. Diabetes Care. 2007;30:911-7.

45. Shin D, Pregenzer G, Gardin JM. Erectile dysfunction: a disease marker for cardiovascular disease. Cardiol Rev. 19:5-11.
46. Brüning JC, Gautam D, Burks DJ, Gillette J, Schubert M, Orban $\mathrm{PC}$, et al. Role of brain insulin receptor in control of body weight and reproduction. Science. 2000;289:2122-5.

47. Prasad DS, Kabir Z, Devi KR, Dash AK, Das BC. Subclinical atherosclerosis and silent myocardial ischaemia in patients with type 2 diabetes: a protocol of a clinico-observational study. Open Hear. 2014;1:e00100.

48. Haffner SM, Lehto S, Rönnemaa T, Pyörälä K, Laakso M. Mortality from coronary heart disease in subjects with type 2 diabetes and in nondiabetic subjects with and without prior myocardial infarction. N Engl J Med. 1998;339:229-34.

49. Sukhija R, Dhanwal D, Gambhir DS, Dewan R. Silent myocardial ischaemia in patients with type II diabetes mellitus and its relation with autonomic dysfunction. Indian Heart J. 52:540-6.

50. Fukui M, Tanaka M, Okada H, Iwase H, Mineoka Y, Senmaru T, et al. Five-item version of the international index of erectile function correlated with albuminuria and subclinical atherosclerosis in men with type 2 diabetes. J Atheroscler Thromb. 2011;18:991-7.

51. Jackson G, Rosen RC, Kloner RA, Kostis JB. The second Princeton consensus on sexual dysfunction and cardiac risk: new guidelines for sexual medicine. J Sex Med. 2006;3:28-36 discussion 36.

52. Nygård $\mathrm{O}$, Nordrehaug JE, Refsum H, Ueland PM, Farstad M, Vollset SE. Plasma homocysteine levels and mortality in patients with coronary artery disease. N Engl J Med. 1997;337:230-6.

53. Wang C, Huang Y. [Hyperhomocysteinemia and erectile dysfunction: an update]. Zhonghua Nan Ke Xue. 2011;17:1019-22.

54. Hecht MJ, Neundörfer B, Kiesewetter F, Hilz MJ. Neuropathy is a major contributing factor to diabetic erectile dysfunction. Neurol Res. 2001;23:651-4.

55. Pegge NC, Twomey AM, Vaughton K, Gravenor MB, Ramsey MW, Price DE. The role of endothelial dysfunction in the pathophysiology of erectile dysfunction in diabetes and in determining response to treatment. Diabet Med. 2006;23:873-8.

56. Debono M, Cachia E, Cassar A, Calleja N, Mallia M, Vassallo J. Is erectile dysfunction a sentinel symptom for cardiovascular autonomic neuropathy in patients with type 2 diabetes? Andrologia. 2008; $40: 1-6$

57. Gazzaruso C, Giordanetti S, De Amici E, Bertone G, Falcone C, Geroldi D, et al. Relationship between erectile dysfunction and silent myocardial ischemia in apparently uncomplicated type 2 diabetic patients. Circulation. 2004;110:22-6.

58. Vinik AI, Maser RE, Mitchell BD, Freeman R. Diabetic autonomic neuropathy. Diabetes Care. 2003;26:1553-79.

59. Bleustein CB, Arezzo JC, Eckholdt H, Melman A. The neuropathy of erectile dysfunction. Int J Impot Res. 2002;14:433-9.

60. Burchardt M, Burchardt T, Baer L, Kiss AJ, Pawar RV, Shabsigh A, et al. Hypertension is associated with severe erectile dysfunction. J Urol. 2000;164:1188-91.

61. Korhonen PE, Ettala O, Kautiainen H, Kantola I. Factors modifying the effect of blood pressure on erectile function. J Hypertens. 2015;33(5):975-80.

62. Jensen J, Lendorf A, Stimpel H, Frost J, Ibsen H, Rosenkilde P. The prevalence and etiology of impotence in 101 male hypertensive outpatients. Am J Hypertens. 1999;12:271-5.

63. Chang S-T, Chu C-M, Hsu J-T, Lin P-C, Shee J-J. Surveillance of cardiovascular risk factors for outpatients in different erectile dysfunction severity. Int J Impot Res. 21:116-21.

64. Javaroni V, Neves MF. Erectile dysfunction and hypertension: impact on cardiovascular risk and treatment. Int J Hypertens. 2012;2012:627278.

65. Bansal S Sexual dysfunction in hypertensive men. A critical review of the literature. Hypertension. 1988;12:1-10.

66. Baumhäkel M, Schlimmer N, Kratz M, Hackett G, Hacket G, Jackson $\mathrm{G}$, et al. Cardiovascular risk, drugs and erectile function-a systematic analysis. Int J Clin Pract. 2011;65:289-98. 
67. Böhm M, Baumhäkel M, Teo K, Sleight P, Probstfield J, Gao P, et al. Erectile dysfunction predicts cardiovascular events in highrisk patients receiving telmisartan, ramipril, or both: the ONgoing Telmisartan Alone and in combination with Ramipril Global Endpoint Trial/Telmisartan Randomized AssessmeNt Study in ACE iNtoler. Circulation. 2010;121:1439-46. doi:10.1161/ CIRCULATIONAHA.109.864199.

68. Fogari R, Zoppi A. Effect of antihypertensive agents on quality of life in the elderly. Drugs Aging. 2004;21:377-93.

69. Chen Y, Cui S, Lin H, Xu Z, Zhu W, Shi L, et al. Losartan improves erectile dysfunction in diabetic patients: a clinical trial. Int $\mathrm{J}$ Impot Res. 24:217-20.

70. Yang L, Yu J, Ma R, Zhao F, Lin X, Liu P, et al. The effect of combined antihypertensive treatment (felodipine with either irbesartan or metoprolol) on erectile function: a randomized controlled trial. Cardiology. 2013;125:235-41.

71. Lim AK. Diabetic nephropathy - complications and treatment. Int J Nephrol Renov Dis. 2014;7:361-81. doi:10.2147/IJNRD. S40172.

72. Huang C, Kim Y, Caramori MLA, Fish AJ, Rich SS, Miller ME, et al. Cellular basis of diabetic nephropathy: II. The transforming growth factor-beta system and diabetic nephropathy lesions in type 1 diabetes. Diabetes. 2002;51:3577-81.

73. Chuang Y-C, Chung M-S, Wang P-W, Lee W-C, Chen C-D, Chang $\mathrm{H}-\mathrm{W}$, et al. Albuminuria is an independent risk factor of erectile dysfunction in men with type 2 diabetes. J Sex Med. 2012;9:1055-64.

74. Blans MCA, Visseren FLJ, Banga JD, Hoekstra JBL, van der Graaf Y, Diepersloot RJA, et al. Infection induced inflammation is associated with erectile dysfunction in men with diabetes. Eur J Clin Investig. 2006;36:497-502.

75. Fakjian N, Hunter S, Cole GW, Miller J. An argument for circumcision. Prevention of balanitis in the adult. Arch Dermatol. 1990;126:1046-7.

76. El-Sakka AITK. Vascular impairment of erection in patients with diabetes and peyronie's disease: is that accumulative? J Sex Med. 2009;6(6):1736-42.

77. Tefekli A, Kandirali EEB. Peyronie's disease: a silent consequence of diabetes mellitus. Asian J Androl. 2006;8(1):75-9.

78. Bromage SJ, Crump A, Pearce I. Phimosis as a presenting feature of diabetes. BJU Int. 2008;101:338-40.

79. De Berardis G, Pellegrini F, Franciosi M, Belfiglio M, Di Nardo B, Greenfield S, et al. Identifying patients with type 2 diabetes with a higher likelihood of erectile dysfunction: the role of the interaction between clinical and psychological factors. J Urol. 2003;169: 1422-8.

80. McCulloch DK, Hosking DJ, Tobert A. A pragmatic approach to sexual dysfunction in diabetic men: psychosexual counselling. Diabet Med. 3:485-9.

81. Condorelli RA, Calogero AE, Vicari E, Favilla V, Morgia G, Cimino S, et al. Vascular regenerative therapies for the treatment of erectile dysfunction: current approaches. Andrology. 2013;1: 533-40.

82. Isidori AM, Buvat J, Corona G, Goldstein I, Jannini EA, Lenzi A, Porst H, Salonia A, Traish AMMM. A critical analysis of the role of testosterone in erectile function: from pathophysiology to treatment-a systematic review. Eur Urol. 2014;65:99-112.

83. Aversa A, Francomano D, Lenzi A. Does testosterone supplementation increase PDE5-inhibitor responses in difficult-to-treat erectile dysfunction patients? Expert Opin Pharmacother. 2015;16(5): 625-8.

84. Martin A Kathryn. Treatment of male sexual dysfunction 2013. http://www.uptodate.com/contents/evaluation-of-male-sexualdysfunction Accessed 14 May 2014.

85. Schmidt HM, Munder T, Gerger H, Frühauf S, Barth J. Combination of psychological intervention and phosphodiesterase-5 inhibitors for erectile dysfunction: a narrative review and meta-analysis. J Sex Med. 2014;11:1376-91.

86. Rendell MS, Rajfer J, Wicker PA, Smith MD. Sildenafil for treatment of erectile dysfunction in men with diabetes: a randomized controlled trial. Sildenafil Diabetes Study Group. JAMA. 1999;281:421-6.

87. Schover LR, Fouladi RT, Warneke CL, Neese L, Klein EA, Zippe $\mathrm{C}$, et al. The use of treatments for erectile dysfunction among survivors of prostate carcinoma. Cancer. 2002;95:2397-407.

88. Zippe CD, Kedia AW, Kedia K, Nelson DR, Agarwal A. Treatment of erectile dysfunction after radical prostatectomy with sildenafil citrate (Viagra). Urology. 1998;52:963-6.

89. Morales A, Gingell C, Collins M, Wicker PA, Osterloh IH. Clinical safety of oral sildenafil citrate (VIAGRA) in the treatment of erectile dysfunction. Int J Impot Res. 1998;10:69-73 discussion 73-4.

90. Bruzziches R, Francomano D, Gareri P, Lenzi A, Aversa A. An update on pharmacological treatment of erectile dysfunction with phosphodiesterase type 5 inhibitors. Expert Opin Pharmacother. 2013;14:1333-44.

91. Goldstein I, Young JM, Fischer J, Bangerter K, Segerson T, Taylor T. Vardenafil, a new phosphodiesterase type 5 inhibitor, in the treatment of erectile dysfunction in men with diabetes: a multicenter double-blind placebo-controlled fixed-dose study. Diabetes Care. 2003;26:777-83.

92. Jannini EA, McMahon C, Chen J, Aversa A, Perelman M. The controversial role of phosphodiesterase type 5 inhibitors in the treatment of premature ejaculation. J Sex Med. 2011;8:2135-43. doi:10.1111/j.1743-6109.2011.02401.x.

93. Borer J, Armstrong P. Proceedings of the 99th meeting of the Food and Drug Administration Cardiovascular and Renal Drugs Advisory Committee. May 29th and 30th, 2003. Circulation. 2003;107:e9052. doi:10.1161/01.CIR.0000082691.46188.C8.

94. Padma-Nathan H Efficacy and tolerability of tadalafil, a novel phosphodiesterase 5 inhibitor, in treatment of erectile dysfunction. Am J Cardiol. 2003;92:19M-25M.

95. Koka S, Das A, Salloum FN, Kukreja RC. Phosphodiesterase-5 inhibitor tadalafil attenuates oxidative stress and protects against myocardial ischemia/reperfusion injury in type 2 diabetic mice. Free Radic Biol Med. 2013;60:80-8.

96. Weeks JL, Zoraghi R, Beasley A, Sekhar KR, Francis SH, Corbin JD. High biochemical selectivity of tadalafil, sildenafil and vardenafil for human phosphodiesterase 5A1 (PDE5) over PDE11A4 suggests the absence of PDE11A4 cross-reaction in patients. Int J Impot Res. 17:5-9.

97. Goldstein I, McCullough AR, Jones LA, Hellstrom WJ, Bowden $\mathrm{CH}$, Didonato K, et al. A randomized, double-blind, placebocontrolled evaluation of the safety and efficacy of avanafil in subjects with erectile dysfunction. J Sex Med. 2012;9:1122-33.

98. Goldstein I, Jones LA, Belkoff LH, Karlin GS, Bowden CH, Peterson CA, et al. Avanafil for the treatment of erectile dysfunction: a multicenter, randomized, double-blind study in men with diabetes mellitus. Mayo Clin Proc. 2012;87:843-52.

99. Ortaç M, Çayan S, Çalișkan MK, Yaman MÖ, Okutucu TM, Semerci MB, et al. Efficacy and tolerability of udenafil in Turkish men with erectile dysfunction of psychogenic and organic aetiology: a randomized, double-blind, placebo-controlled study. Andrology. 2013;1:549-55.

100. Salem EA, Kendirci M, Hellstrom WJG. Udenafil, a long-acting PDE5 inhibitor for erectile dysfunction. Curr Opin Investig Drugs. 2006;7:661-9.

101. Moon DG, Yang DY, Lee CH, Ahn TY, Min KS, Park K, et al. A therapeutic confirmatory study to assess the safety and efficacy of Zydena (udenafil) for the treatment of erectile dysfunction in male patients with diabetes mellitus. J Sex Med. 2011;8:2048-61. 
102. Ding H, Du W, Wang H, Zhang L, Wang Z, Du C, et al. Efficacy and safety of udenafil for erectile dysfunction: a meta-analysis of randomized controlled trials. Urology. 2012;80:134-9.

103. Cho MC, Paick J-S. Udenafil for the treatment of erectile dysfunction. Ther Clin Risk Manag. 2014;10:341-54.

104. Du W, Li J, Fan N, Shang P, Wang Z, Ding H. Efficacy and safety of mirodenafil for patients with erectile dysfunction: a metaanalysis of three multicenter, randomized, double-blind, placebocontrolled clinical trials. Aging Male. 2013;17(2):107-11.

105. Malavige LS, Levy JC. Erectile dysfunction in diabetes mellitus. J Sex Med. 2009;6:1232-47.

106. Redrow GP, Thompson CM, Wang R. Treatment strategies for diabetic patients suffering from erectile dysfunction: an update. Expert Opin Pharmacother. 2014;15:1827-36.

107. Lu C-C, Jiann B-P, Sun C-C, Lam H-C, Chu C-H, Lee J-K. Association of glycemic control with risk of erectile dysfunction in men with type 2 diabetes. J Sex Med. 2009;6:1719-28.

108. Gupta BP, Murad MH, Clifton MM, Prokop L, Nehra A, Kopecky SL. The effect of lifestyle modification and cardiovascular risk factor reduction on erectile dysfunction: a systematic review and meta-analysis. Arch Intern Med. 2011;171:1797-803.

109. Wing RR, Rosen RC, Fava JL, Bahnson J, Brancati F, Gendrano Iii INC, et al. Effects of weight loss intervention on erectile function in older men with type 2 diabetes in the Look AHEAD trial. J Sex Med. 2010;7:156-65.

110. Isidori AM, Lenzi A. Risk factors for androgen decline in older males: lifestyle, chronic diseases and drugs. J Endocrinol Investig. 2005;28:14-22.

111. Esposito K, Giugliano F, Di Palo C, Giugliano G, Marfella R, D'Andrea F, et al. Effect of lifestyle changes on erectile dysfunction in obese men: a randomized controlled trial. JAMA. 2004;291:2978-84.

112. Vardi M, Nini A. Phosphodiesterase inhibitors for erectile dysfunction in patients with diabetes mellitus. Cochrane Database Syst Rev 2007:CD002187.

113. Cheng E Real-life safety and efficacy of vardenafil in the treatment of erectile dysfunction-results from 30,010 U.S. patients. J Sex Med. 2007;4(2):432-9.

114. Fonseca V, Seftel A, Denne J, Fredlund P. Impact of diabetes mellitus on the severity of erectile dysfunction and response to treatment: analysis of data from tadalafil clinical trials. Diabetologia. 2004;47:1914-23.

115. Vickers MA, Satyanarayana R. Phosphodiesterase type 5 inhibitors for the treatment of erectile dysfunction in patients with diabetes mellitus. Int J Impot Res. 2002;14:466-71.

116. Jannini EA, Isidori AM, Gravina GL, Aversa A, Balercia G, Bocchio M, et al. The ENDOTRIAL study: a spontaneous, open-label, randomized, multicenter, crossover study on the efficacy of sildenafil, tadalafil, and vardenafil in the treatment of erectile dysfunction. J Sex Med. 2009;6:2547-60.

117. Israilov S, Shmuely J, Niv E, Engelstein D, Livne P, Boniel J. Evaluation of a progressive treatment program for erectile dysfunction in patients with diabetes mellitus. Int J Impot Res. 2005;17:431-6.

118. Blonde L Sildenafil citrate for erectile dysfunction in men with diabetes and cardiovascular risk factors: a retrospective analysis of pooled data from placebo-controlled trials. Curr Med Res Opin. 2006;22:2111-20.

119. Boulton AJ, Selam JL, Sweeney M, Ziegler D. Sildenafil citrate for the treatment of erectile dysfunction in men with type II diabetes mellitus. Diabetologia. 2001;44:1296-301.

120. Ishii N, Nagao K, Fujikawa K, Tachibana T, Iwamoto Y, Kamidono S. Vardenafil 20-mg demonstrated superior efficacy to 10 -mg in Japanese men with diabetes mellitus suffering from erectile dysfunction. Int J Urol. 2006;13:1066-72.
121. Ziegler D, Merfort F, van Ahlen H, Yassin A, Reblin T, Neureither M. Efficacy and safety of flexible-dose vardenafil in men with type 1 diabetes and erectile dysfunction. J Sex Med. 2006;3: 883-91.

122. Buvat J, van Ahlen H, Schmitt H, Chan M, Kuepfer C, Varanese L. Efficacy and safety of two dosing regimens of tadalafil and patterns of sexual activity in men with diabetes mellitus and erectile dysfunction: scheduled use vs. on-demand regimen evaluation (SURE) study in 14 European countries. J Sex Med. 2006;3:51220.

123. Hatzichristou D, Gambla M, Rubio-Aurioles E, Buvat J, Brock GB, Spera G, et al. Efficacy of tadalafil once daily in men with diabetes mellitus and erectile dysfunction. Diabet Med. 2008;25: $138-46$.

124. Kyle JA, Brown DA, Hill JK. Avanafil for erectile dysfunction. Ann Pharmacother. 2013;47:1312-20.

125. Hackett G, Cole N, Bhartia M, Kennedy D, Raju J, Wilkinson P. Testosterone replacement therapy with long-acting testosterone undecanoate improves sexual function and quality-of-life parameters vs. placebo in a population of men with type 2 diabetes. J Sex Med. 2013;10:1612-27.

126. Jones TH, Arver S, Behre HM, Buvat J, Meuleman E, Moncada I, et al. Testosterone replacement in hypogonadal men with type 2 diabetes and/or metabolic syndrome (the TIMES2 study). Diabetes Care. 2011;34:828-37.

127. Jannini EA, Isidori AM, Aversa A, Lenzi A, Althof SE. Which is first? The controversial issue of precedence in the treatment of male sexual dysfunctions. J Sex Med. 2013;10:2359-69.

128. Spitzer M, Basaria S, Travison TG, Davda MN, Paley A, Cohen $\mathrm{B}$, et al. Effect of testosterone replacement on response to sildenafil citrate in men with erectile dysfunction: a parallel, randomized trial. Ann Intern Med. 2012;157:681-91.

129. Buvat J, Montorsi F, Maggi M, Porst H, Kaipia A, Colson MH, et al. Hypogonadal men nonresponders to the PDE5 inhibitor tadalafil benefit from normalization of testosterone levels with a $1 \%$ hydroalcoholic testosterone gel in the treatment of erectile dysfunction (TADTEST study). J Sex Med. 2011;8:284-93.

130. Isidori AM, Giannetta E, Pozza C, Bonifacio V, Isidori A. Androgens, cardiovascular disease and osteoporosis. J Endocrinol Investig. 2005;28:73-9.

131. Corona G, Maseroli E, Rastrelli G, Isidori AM, Sforza A, Mannucci E, et al. Cardiovascular risk associated with testosterone-boosting medications: a systematic review and meta-analysis. Expert Opin Drug Saf. 2014;13:1327-51.

132. Padma-Nathan H, Hellstrom WJ, Kaiser FE, Labasky RF, Lue TF, Nolten WE, et al. Treatment of men with erectile dysfunction with transurethral alprostadil. Medicated Urethral System for Erection (MUSE) Study Group. N Engl J Med. 1997;336:1-7.

133. Li MK, Lim PH, Wong MY, Fok A, Chia SJ, Consigliere D, et al. Transurethral alprostadil for the treatment of erectile dysfunction: results of a multicentre trial. Ann Acad Med Singap. 2000;29: $727-31$.

134. Hanchanale V, Eardley I. Alprostadil for the treatment of impotence. Expert Opin Pharmacother. 2014;15:421-8.

135. Costa P, Potempa A-J. Intraurethral alprostadil for erectile dysfunction: a review of the literature. Drugs. 2012;72:2243-54.

136. Urciuoli R, Cantisani TA, Carlini M, Giuglietti M, Botti FM. Prostaglandin E1 for treatment of erectile dysfunction. Cochrane Database Syst Rev. 2004;2:CD001784.

137. Perimenis P, Gyftopoulos K, Athanasopoulos A, Barbalias G. Diabetic impotence treated by intracavernosal injections: high treatment compliance and increasing dosage of vaso-active drugs. Eur Urol. 2001;40:398-402 discussion 403.

138. Coombs PG, Heck M, Guhring P, Narus J, Mulhall JP. A review of outcomes of an intracavernosal injection therapy programme. BJU Int. 2012;110:1787-91. 
139. Das A, Durrant D, Salloum FN, Xi L, Kukreja RC. PDE5 inhibitors as therapeutics for heart disease, diabetes and cancer. Pharmacol Ther. 2014;147:12-21.

140. Giannetta E, Isidori AM, Galea N, Carbone I, Mandosi E, Vizza $\mathrm{CD}$, et al. Chronic inhibition of cGMP phosphodiesterase 5A improves diabetic cardiomyopathy: a randomized, controlled clinical trial using magnetic resonance imaging with myocardial tagging. Circulation. 2012;125:2323-33.

141. Koka S, Aluri HS, Xi L, Lesnefsky EJ, Kukreja RC. Chronic inhibition of phosphodiesterase 5 with tadalafil attenuates mitochondrial dysfunction in type 2 diabetic hearts: potential role of NO/SIRT1/PGC-1 $\alpha$ signaling. Am J Physiol Heart Circ Physiol. 2014;306:H1558-68.

142. Deyoung L, Chung E, Kovac JR, Romano W, Brock GB. Daily use of sildenafil improves endothelial function in men with type 2 diabetes. J Androl. 2012;33:176-80.

143. Kim J, Montagnani M, Koh KK, Quon MJ. Reciprocal relationships between insulin resistance and endothelial dysfunction: molecular and pathophysiological mechanisms. Circulation. 2006;113:1888-904.

144. Williams SB, Cusco JA, Roddy MA, Johnstone MT, Creager MA. Impaired nitric oxide-mediated vasodilation in patients with noninsulin-dependent diabetes mellitus. J Am Coll Cardiol. 1996;27: 567-74.

145. Kloner RA, Comstock G, Levine LA, Tiger S, Stecher VJ. Investigational noncardiovascular uses of phosphodiesterase-5 inhibitors. Expert Opin Pharmacother. 2011;12:2297-313.

146. Desouza C, Parulkar A, Lumpkin D, Akers D, Fonseca VA. Acute and prolonged effects of sildenafil on brachial artery flowmediated dilatation in type 2 diabetes. Diabetes Care. 2002;25: 1336-9.

147. Aversa A, Vitale C, Volterrani M, Fabbri A, Spera G, Fini M, et al. Chronic administration of Sildenafil improves markers of endothelial function in men with type 2 diabetes. Diabet Med. 2008;25: $37-44$.

148. Stirban A, Laude D, Elghozi J-L, Sander D, Agelink MW, Hilz MJ, et al. Acute effects of sildenafil on flow mediated dilatation and cardiovascular autonomic nerve function in type 2 diabetic patients. Diabetes Metab Res Rev. 2009;25:136-43.

149. Schäfer A, Fraccarollo D, Pförtsch S, Flierl U, Vogt C, Pfrang J, et al. Improvement of vascular function by acute and chronic treatment with the PDE-5 inhibitor sildenafil in experimental diabetes mellitus. Br J Pharmacol. 2008;153:886-93.

150. Aversa A, Greco E, Bruzziches R, Pili M, Rosano G, Spera G. Relationship between chronic tadalafil administration and improvement of endothelial function in men with erectile dysfunction: a pilot study. Int J Impot Res. 2007;19:200-7.

151. Grover-Páez F, Villegas Rivera G, Guillén OR. Sildenafil citrate diminishes microalbuminuria and the percentage of A1c in male patients with type 2 diabetes. Diabetes Res Clin Pract. 2007;78: 136-40.

152. Santi D, Giannetta E, Isidori AM, Vitale C, Aversa A, Simoni M. THERAPY OF ENDOCRINE DISEASE: effects of chronic use of phosphodiesterase inhibitors on endothelial markers in type 2 diabetes mellitus: a meta-analysis. Eur J Endocrinol. 2015;172(3): R103-14.

153. Rosano GMC, Aversa A, Vitale C, Fabbri A, Fini M, Spera G. Chronic treatment with tadalafil improves endothelial function in men with increased cardiovascular risk. Eur Urol. 2005;47:214 20 discussion 220-2.

154. Van der Mieren G, Nevelsteen I, Vanderper A, Oosterlinck W, Flameng W, Herijgers P. Angiotensin-converting enzyme inhibition and food restriction in diabetic mice do not correct the increased sensitivity for ischemia-reperfusion injury. Cardiovasc Diabetol. 2012;11:89.

155. Przyklenk K, Maynard M, Greiner DL, Whittaker P. Cardioprotection with postconditioning: loss of efficacy in murine models of type- 2 and type- 1 diabetes. Antioxid Redox Signal. 2011;14:781-90.

156. Varma A, Das A, Hoke NN, Durrant DE, Salloum FN, Kukreja RC. Anti-inflammatory and cardioprotective effects of tadalafil in diabetic mice. PLoS One. 2012;7:e45243.

157. Kukreja RC, Salloum FN, Das A, Koka S, Ockaili RA, Xi L. Emerging new uses of phosphodiesterase-5 inhibitors in cardiovascular diseases. Exp Clin Cardiol. 2011;16:e30-5.

158. Shakir SA, Wilton LV, Boshier A, Layton D, Heeley E. Cardiovascular events in users of sildenafil: results from first phase of prescription event monitoring in England. BMJ. 2001;322:651-2.

159. Opie LH, Commerford PJ, Gersh BJ, Pfeffer MA. Controversies in ventricular remodelling. Lancet 2006;367:356-67.

160. Guazzi M, Vicenzi M, Arena R. Phosphodiesterase 5 inhibition with sildenafil reverses exercise oscillatory breathing in chronic heart failure: a long-term cardiopulmonary exercise testing placebo-controlled study. Eur J Heart Fail. 2012;14:82-90.

161. Aronson D, Bartha P, Zinder O, Kerner A, Shitman E, Markiewicz $\mathrm{W}$, et al. Association between fasting glucose and C-reactive protein in middle-aged subjects. Diabet Med. 2004;21:39-44. 